\title{
Analysis of the Artistic Style of 36 Aire Di Steli Antico
}

\author{
Yaomin, Liu yang \\ School of Music of Chengdu Normal University, Sichuan, China \\ School of Music of Chengdu Normal University, Sichuan, China
}

Key words: 36 aire di steli antico, classicism style, romanticism style

\begin{abstract}
Compared with E.Curtis (1875-1937) and F.Tosti (1846-1916) who almost has no opera works, Donaudy is one Italian composer who was ignored by contemporary music circle and up to now, the number of document literature on him is relatively less, even like the authoritative Music Encyclopedia The New Grove Dictionary of Music and Musicians does not record it. The existing works of Donaudy, except for the still widely promoted 36 aire di steli antico, the others are seldom in printed. In this paper, the author try to dissect the artistic style and features of Donaudy's artistic songs through the analysis of 36 aire di steli antico, on which basis, try to know the artistic style and features of Italian artistic songs in the 19th more comprehensively and deeply.

In the 19th, which period is the period of great prosperity for Italian opera, Stefano Donaudy(1879-1925) was born in the Palermo of Italian Sicily and in his adolescent period, he studied in Vincenzo Bellini Conservatory of Palermo for the learning of harmony, counterpoint and composing skills in Baroque and classical period, besides, his teacher is famous Italian composer and conductor Guglielmo Zuelli(1859-1941). Donaudy’s musical performance is early-maturing. In 1892, Donaudy of 13 years old had written his first opera Folchetto and famous artistic song Vaghissima sembianza. Hereafter Donaudy had been committed to the songs writing and he had finished six opera works, piano opusculum, chamber music and instrumental music etc. In 1925, 46-year old Donaudy died in Napoli.
\end{abstract}

\section{Classicism Style of 36 Aire Di Steli Antico}

In the middle and later period of nineteenth century, the liberation and unification Risorgimento rose in Italy and Donaudy, same with many other composers, began to re-examine and try hard to go back to the Italian style in renaissance period. He was influenced deeply by Rimsky-Korsakov (1844-1908) etc. Nationalistic composers and he had tried to borrow the Gregorian Chant, church music mode and Italian classical composition technique of Baroque time, finally, the artistic style with obvious personal characteristics and great difference to such historical background formed.

The classicism style of 36 aire di steli antico is mainly reflected in the works style and it is firstly published by famous publishing house Ricordi in 1918, besides, republished in 1922. Analyzing from the works types or forms, the 36 songs were written basically on the basis of Baroque musical types or the musical types in more earlier period and they include 9 Arias, 3 Ariettas, 3 Ballatellas, 5 Canzones, 5 Canzonettas, 2 Frottolas 3 Madrigale, 2 Maggiolata and 4 Villanella, most of which belong to different Italian songs patterns in 14th, 15th, 16th and 17th, besides, their structures mainly are the classicism structures, like, $A B 、 A B A 、 A B A B$ etc.

Aria: the aria in 16th and 17th generally is strophic song and is one singing type of solo, two-part or the above song with instrumental accompaniment. In the early period of 17th century, the representative Italian collection of aria is the Le nuove musiche written by Caccini (1500-1618) and 
it includes 10 arias, most of which adopt the triple time and consistently use the structure form of eight Phrase with the adding of 2-3 short sentences.

Arietta: comparing with aria, it has no obvious difference, however, generally, its musical structure is relatively short and small, besides, musical vocabulary is relatively simple.

Canzone: canzone originally refers to the lyric poetry of sound music and it has deep relation with Frottola and Madrigale. In the end of 15th and the beginning of 16th, canzone, as one pattern of Frottola had got rapid development and because it has the content and structure of poetry, it had gradually separated itself from the frottola and become one important source of madrigale.

Canzonetta: it is a normal diminutive of canzone, which is popular in Italy from 16th to 18th, besides, 5 songs are included in the complete collection. Canzonetta and canzone, compared with the other types, are richer in the rhythmicity and symmetry of poem, besides, at the time of half cadence and cadence, they often use the writing technique similar to commiato.

Frottola: in 15th and 16th, there is one mundane tanka intensively popular in Italy, especially in the period from 1470 to 1530, the frottola is in full flourish in the north of Italy and since 1530, it has gradually evolved into madrigale. Musically, the frottola generally adopts the monophonic melody, repetitive and clear rhythmic pattern. Frottola not only has great significance to the forming of madrigale, also has great significance to French chanson.

Madrigale: in the first half of 16th , one kind of part song spreading from Italy to the whole Europe has reached its peak in the early period of Baroque. Different from the Strophic forms, most of the madrigale belong to the through-composed songs and the composers have tried to express the personal emotion and individuality, besides, they have made more free play in the writing.

Maggiolata: this word originates in Maggio. According to traditional Italian Tuscany custom, on May 1st of each year, the young men will stick branches before the door of their beloved women to express their affection, gradually, this custom has evolved into one singing type and form. The maggiolata in 15th takes the melody of strophic forms as the main part, and to 16th, it gradually evolves to the light madrigale.

Villanella: it originates in Latin villanus, meaning farmer, peasant. Villanella generally refers in particular to the country tune prevailing in Napoli area of Italy and singing in Napoli local dialect. Compared with the canzonetta, the region and language limitation of villanella is strong; compared with madrigale, villanella lays emphasis on the asymmetry of musical form and it often use the parallel fifths, besides, most of its themes are village.

\section{Romanticism Style of 36 Aire Di Steli Antico}

As we all known, the romanticism music in the middle period of 19th has governed the European continent completely. In the process of artistic creation, Donaudy has been influenced naturally by the romanticism musical style and the concrete representation is as the two following aspects.

The Italian opera and artistic songs in Baroque and classical period have been fettered by religious music,besides, the parallel going of melody and thorough bass is the common used writing technique for the composers at that time, such as the Ninaldo written by F.Handel(1685-1759). The Italian song in romanticism period has separated itself from the influence of religious songs totally and under the influence of Rossini, Donizetti, Bellini etc. opera masters, the melodic line of Donaudy artistic songs have become gorgeous and exquisite, besides, the rhythm and speed are diverse, like the large-number and skillful use of harmony and modulation etc. Therefore, his works are totally different from the Italian operas aria or bel canto in Baroque and classical periods, besides, it is obvious for the differences between the other Italian artistic songs with the Tosti as the representative in 19th century. 
Firstly, Donaudy is good at the change and conflict design of musical works. In colors of music, Donaudy often adopt large number of crescendo, decrescendo and sandhi, skipping music comparison or large number of modality and tonality changes to strengthen the musical contradiction and conflict. In speed, the Italian artistic songs in Baroque and classical period mostly are indicated the fixed speed and are sung in tempo, however, Donaudy has strong hobby of speed changes, such as the frequently appeared marks: a tempo, allargando, rallentando, ritardando etc. Apart from the above, the lyrics design, emotion changes often have the dramatic conflict between love and hate, thinking and unspoken words,such musical theatricality and change is one of the distinguishing feature that the romanticism music pursues.

Secondly, due to his experience of being a teacher, Donaudy has more exquisite requirement and control of singing processing, therefore, we find that, compared with the other composers, Donaudy's artistic songs have richer and more detail music score marks. For example, for the processing of cadenzas, the Italian singers in Baroque and classical period generally make free adding or decoration according to their own skills and hobby, such as for the musical form ABA, the frequent adding of appoggiatura and echo etc. in the repeating section A. However, Donaudy will make a detail mark of the decoration tone in cadenza section. Apart from being good at using gorgeous, beautiful melody, various rhythm and texture, Donaudy is also good at processing music through various expression and speed. According to the statistics, the number of expression terms in 36 Aire Di Steli Antico can reach 129. The frequent using of allarg 、 ritartando、 tempo 、 atempo such speed marks; the large number of application of con-, poco- and dolce etc. expression terms. Only in the work of Ah,che odor di buono, the number of expression terms,speed terms and dynamics terms is about over 40.

Romanticism music gradually prevails over the countries in Europe along with the forming of Germany and Austrian romanticism literature and art ideological trend, and its main content is the profound contradiction between ideal and reality, besides, through various lyric themes to express the musician's desire and pursuing of freedom and happy life. Therefore, romanticism musician pay great attention to the combination of music and literature, besides, they not only have imagination on musical content, also express their emotion and create ideal condition through literature. Bold, free and rigorous poem is just the requirement for composers' thought and imagination expression. The 19th Germany Lied in its full blooming period has also been regarded as one of the representative expression method of this artistic type and it has completed the perfect harmony between music and poetry in less than one century from its beginning to refulgence, and then it has become one important part of the European romanticism music, finally, a large number of great Lied composers have come into being like, Schumann, Schubert, Brahms and Wolf etc.

Donaudy is known by European people is not in Italy, but in Hamburg, Germany in 1902, at which time, only 23-year old Donaudy has performed his first work, German work--Theodor korner. Donaudy, in his youth and lived in Germany, has been influenced profoundly by the aesthetic idea of Germany and Austrian Lied since the 18th century in his later songs composing process, especially in the aspect of poetry selection and use, musical image shaping, he has devoted much effort. For the expression forms, melody sources, tonality changing, even the different musical figures and artistic conception in accompaniment, he can get enlightenment from the poetry. He uses the musical vocabularies to synthesize the events, figures, scenes, emotion and feelings into one perfect whole. Apart from the Italian traditional well organized sonnet, he also like selecting the new poetry that can stimulate his creative enthusiasm and has the features of small and fine structure, deep thinking, exquisite sensibility and profound meaning, besides, he often takes use of the asymmetry of the structure to give arise to stronger musical imagination and conflict. The lyric 
of 36 Aire Di Steli Antico has adopted the poetry of his poet brother--Alberto Donaudy(1880-1941) and it is said that the two brothers often get together to think over the literature vocabularies and sentences so that to make the poem and music be more harmony and appropriate. Donaudy's love and deep study on poetry may be one of the important reasons for this set of 36 Aire Di Steli Antico to be widely spread to today.

\section{Conclusion}

Compared to the great achievement made by Italian opera, the Italian artistic songs in 19th century are generally thought not good enough than the Germany and Austrian songs no matter in skill or in artistry. However, the author's opinion is that the 36 Aire Di Steli Antico, to a certain degree, can totally be on a par with the Germany and Austrian artistic songs, besides, the romantic feeling of vocal music works covered by classic type of appearance has made the Italian songs be richer in its artistic expression forms and connotation and has made great contribution to the development of Italian artistic songs.

\section{Bibliography:}

[1]F.J.Aiello English translations and analyzation of musical forms of "36 Arie di stile antico" by Stefano Donaudy, A Document in partial fulfillment of the requirements for the degree of Doctor of Musical Arts, The University of Oklahoma, School of Music,1985

[2]Sadi The New Grove Dictionary of Music and Musicians[M],Changsha:Literature and Art Publishing House of Hunan, 2012

[3]Shang Jiaxiang Italienisches Liederbuch,[M]Beijing, People's Music Publishing House, 2009

[4]Hatanaka Ryosuke Donaudy 36 Arie di stile antico,[M]Tokyo:Zen-On Music Company LTD, 2010 